\title{
Peningkatan dan Pengendalian Kualitas Produk dengan Menggunakan Metode PDCA (Studi Kasus pada PT. "X")
}

\author{
Abdul Fatah ${ }^{1}$, Ari Zaqi Al-Faritsy ${ }^{2}$ \\ ${ }^{1,2)}$ Fakultas Sains \& Teknologi, Jurusan Teknik Industri, Universitas Teknologi Yogyakarta \\ E-mail: abdulfatah043@gmail.com,ari_zaqi@uty.ac.id
}

\begin{abstract}
ABSTRAK
PT. 'X' merupakan sebuah perusahaan yang memproduksi lemari es lokal dan berorientasi ekspor. Permasalahan yang ditemukan adalah produk cacat lemari es yang di produksi pada tanggal 1 Agustus - 18 Agustus 2018 terdapat persentase cacat yang cukup tinggi sebesar $59.45 \%$ dari sampel total produksi yang dikumpulkan, sehingga produk harus diperbaiki lagi yang mengakibatkan biaya produksi menjadi tinggi. Cacat pada produksi lemari es adalah panel back penyok $15 \%$, urethane foam bocor 68,2\%, dan panel back keluar 16,8\%. Metode penelitian menggunakan PDCA, tahap plan menentukan masalah dan cacat yang akan diperbaiki, tahap do menentukan usulan tindakan perbaikan yang harus dilakukan, tahap check adalah melakukan pemeriksaan sampel produksi setelah implementasi tindakan perbaikan dan tahap action melakukan evaluasi tindakan perbaikan. Berdasarkan kendali mutu menggunakan metode PDCA di PT. "X" diperoleh tindakan korektif seperti peningkatan kesadaran operator, peningkatan standar kerja, pengaturan lingkungan produksi, pemeliharaan perbaikan mesin $u$-bander, dan penggantian $P U$ foam dengan A20. Data produksi pada 19 Agustus 2018 - 31 Agustus 2018 ditemukan jumlah cacat akibat urethane foam bocor, panel back penyok, dan panel back keluar sebanyak 219 unit dengan persentase 36,50\%. Oleh karena itu tindakan korektif yang dilakukan pada penelitian ini mampu meminimalisasi jumlah cacat sebesar $22,95 \%$.
\end{abstract}

Kata kunci : Kualitas, pengendalian kualitas, PDCA, seven tools.

\section{ABSTRACT}

PT. ' $X$ ' is a company that produces refrigerators. The problem that was found was a defective product in the refrigerator that was produced. On 1 August - 18 August 2018, there was a fairly high percentage of defects of 59.45\% of the total production sample, so the product had to be repaired again which resulted in high production costs. The defects that occur are the back panel dented 15\%, urethane foam leaks $68.2 \%$, and the back panel comes out 16.8\%. The research method is carried out using PDCA, the plan stage determines the problems and defects to be repaired, the do stage determines the proposed corrective actions that must be taken, the check stage is to examine the production samples after the implementation of corrective actions and the action stage to evaluate corrective actions. Based on quality control using the PDCA method at PT. " $X$ " obtained corrective actions such as increasing operator awareness, improving working standards, setting the production environment, maintaining $u$-bander engine repairs, and replacing PU foam with A20. Corrective action in production on 19 August 2018 - 31 August 2018 showed the number of defects due to leaking urethane foam, dented back panels, and back panels comes out were 219 units with a percentage of $36.50 \%$. Thus the corrective action taken in this study was able to minimize the number of defects by $22.95 \%$.

Keywords: Quality, quality control, PDCA, seven tools

\section{PENDAHULUAN}

Kualitas produk merupakan faktor penting yang harus dijaga oleh perusahaan dalam meningkatkan daya saing dan loyalitas konsumen, melalui program kualitas yang terencana dan terkendali akan dapat secara efektif menghilangkan pemborosan dan meningkatkan kemampuan perusahaan untuk bersaing. Kualitas dapat diartikan sebagai tingkat atau ukuran kesesuaian suatu produk dengan pemakainya, dalam arti sempit kualitas diartikan sebagai tingkat kesesuaian produk dengan standar yang telah ditetapkan. Jadi kualitas yang baik akan dihasilkan dari proses yang baik dan sesuai dengan kualitas yang telah ditentukan. Kualitas didefinisikan sebagai konsistensi peningkatan atau perbaikan dan penurunan variasi karakteristik dari suatu produk (barang atau jasa) yang dihasilkan agar memenuhi kebutuhan yang telah dispesifikasi guna meningkatkan kepuasan pelanggan (Gasperz, 2005).

Perusahaan PT. 'X' memproduksi Refrigerator. Selama bulan Agustus tahun 2018 terdapat presentase defect yang cukup tinggi yaitu sebesar 59,45\% dari sampel total produksi, sehingga produk harus diperbaiki terlebih dahulu sebelum sampai ke tangan konsumen. Defect yang dimaksud adalah panel back penyok sebesar 14,98\%, urethane foam bocor sebesar 68,19\%, dan panel back keluar sebasar 16,81\% . Adanya hasil produksi yang cacat menunjukan bahwa pengendalian kualitas refrigerator perlu dilakukan analisis mengenai upaya pengendalian kualitas yang diterapkan oleh Bussines Unit Refrigerator dan mencari penyebab 
terjadinya produk cacat serta mencari solusi perbaikan. Kualitas dapat menghasilkan kepuasan konsumen, baik dalam penggunaan produk ataupun pelayanannya (Yulianto dan Alfaritsy, 2015).

Salah satu metode pengendalian kualitas adalah metode PDCA dengan alat bantu Seven Tools, dan $5 \mathrm{~W}+1 \mathrm{H}$. Menurut (Render, 2006), PDCA merupakan model dalam melakukan perbaikan terus - menerus dengan rencanakan, lakukan, periksa, dan tindakan. PDCA merupakan Shewhart Cycle yang digunakan sebagai model panduan perbaikan (Montgomery, 2013). Siklus PDCA umumnya digunakan untuk mengetes dan mengimplementasikan perubahan-perubahan untuk memperbaiki kinerja produk, proses atau suatu sistem di masa yang akan datang.

Siklus PDCA sudah banyak diaplikasikan seperti dalam perbaikan bidang jasa dan manufaktur (Isniah, S., Purba, dkk., 2020), peningkatan kualitas dengan menurunya jumlah cacat dalam proses produksi (Utami, S., Djamal, AH., 2018), meningkatkan hasil pelayanan kesehatan serta menurunkan kesalahan pengobatan (Fauza, Qisti, Kautsar, 2018). Siklus PDCA sebagai metodologi perbaikan kualitas pada product, proses dan layanan ( Sokovic, dkk., 2010). PDCA diaplikasikan dalam peningkatan kualitas dan produktivitas organisasi dan pengurangan limbah yang signifikan dalam produksi kaleng minuman (Silva, Adriana S., dkk., 2017). Dalam penelitian ini siklus PDCA diaplikasikan untuk mencari usulan perbaikan yang dapat meminimalisir terjadinya produk cacat pada produk lemari dengan quality tools yang digunakan berupa seven tools dan $5 \mathrm{~W}+1 \mathrm{H}$.

Alat bantu Seven Tools digunakan untuk menganalisa data kecacatan yang didapat pada proses produksi, Seven Tools merupakan alat atau teknik pengendalian kualitas yang mudah digunakan dalam setiap jenis usaha karena metode, persyaratan keterampilan, maksud dan mekanismenya sangat sederhana dan mudah dimengerti untuk setiap latar belakang pendidikan karyawan di dalam industri (Setyawan, 2016). Seven tools pertama kali diperkenalkan oleh Kaoru Ishikawa pada tahun 1968. Ketujuh alat tersebut adalah Check Sheet, Control Chart, Cause and Effect Diagram, Pareto Diagram, Histogram, Scatter Diagram dan Stratification.

Analisis $5 \mathrm{~W}+1 \mathrm{H}$ adalah suatu metode analisis yang digunakan untuk melakukan penanggulangan terhadap setiap akar permasalahan (Gaspersz, 2005). 5W+1H adalah singkatan dari what, why, who, when,where, dan how. $5 \mathrm{~W}+1 \mathrm{H}$ pada dasarnya adalah suatu metode yang digunakan untuk melakukan investigasi dan penelitian terhadap masalah yang terjadi dalam proses produksi (Utaminingsih, 2018).

\section{METODE PENELITIAN}

Tahapan penelitian dimulai dengan melakukan studi pustaka tentang aplikasi metode PDCA, penggunaan seven tools dan $5 \mathrm{~W}+1 \mathrm{H}$ sebagai metodologi perbaikan kualitas. Penelitian difokuskan pada penyelesaian masalah produk cacat dalam produksi refrigerator, dimana data dikumpulkan secara langsung pada bulan Agustus 2018 dari dokumen produksi perusahaan PT. ' $X$ '. Penelitian dengan tahapan PDCA, tahap plan melakukan pengambilan sample data cacat produksi refrigerator yang disajikan dalam bentuk check sheet, dilakukan analisis peta kendali untuk menganalisis kestabilan proses produksi refrigerator pada saat pengampulan data, serta deskripsi jenis cacat produksi melalui stratification, histogram, dan diagram pareto, dan pada tahap ini juga melakukan survey secara langsung di lantai produksi dalam mengidentifikasi penyebab cacat produksi refrigerator yang disajikan pada cause and effect diagram. Dalam tahap do dilakukan usulan tindakan korektif perbaikan dengan $5 \mathrm{~W}+1 \mathrm{H}$ berdasarkan temuan penyebab cacat produksi. Tindakan korektif ini hasil analisis langsung di lapangan serta berdiskusi dengan kepala unit bisnis refrigerator dalam teknis percobaan implementasi tindakan korektif yang ditemukan pada proses produksi refrigerator, selama implementasi ini data produksi cacat dikumpulkan dalam periode waktu tertentu. Tahap Check melakukan evaluasi dengan membandingkan data cacat produksi sebelum dan sesudah tindakan perbaikan yang disajikan ke dalam peta kendali untuk menganalisis kestabilan proses produksi setelah tindakan perbaikan. Tahap action dilakukan dokumentasi implementasi tindakan korektif dalam perbaikan proses produksi jika hasil evaluasi dapat menurunkan tingkat cacat produksi refrigerator, tetapi jika tidak maka perlu dilakukan lagi penelitian dalam menemukan tindakan korektif yang bisa menurunkan produksi cacat. Nama perusahaan disamarkan demi keamanan informasi perusahaan.

\section{HASIL DAN PEMBAHASAN}

Pengolahan data pada penelitian menggunakan tahapan Plan, Do,Check, Action (PDCA) dengan langkah-langkah sebagai berikut:

\subsection{PLAN}

Pada tahap plan dilakukan beberapa tahapan pengolahan data sebagai berikut :

a. Penentuan Jumlah Sampel

Penentuan sampel dilakukan untuk menentukan ukuran sampel yang dapat diambil pada proses produksi refrigerator. Dari shift 1 jumlah produksi sebanyak 1.326 unit dengan tingkat kesalahan yang dikehandaki $85 \%$. jumlah sampel dapat ditentukan dengan persamaan sebagai berikut:

$$
\mathrm{n}=\frac{1.326}{1.326(0,15)^{2}+1}=43
$$

Maka penentuan jumlah sampel dalam produksi produk refrigerator dapat diambil sampel minimal 43 unit. 


\section{b. Check Sheet}

Tindakan pertama dalam rencana perbaikan proses produksi produk refrigerator pada PT. ' $X$ ' adalah mengumpulkan data sampel berupa jumlah produksi, jumlah cacat, dan jenis jumlah cacat dari pencatatan check sheet yang dilakukan oleh PT. ' $\mathrm{X}$ '. Data sampel yang digunakan adalah pengambilan dari data sampel dalam produksi, data kecacatan produk refrigerator pada tanggal 1 Agustus 2018 - 18 Agustus 2018.

Tabel 1 Check Sheet (Before Improvement)

\begin{tabular}{|c|c|c|c|c|c|c|c|}
\hline \multirow[t]{2}{*}{ No } & \multirow[t]{2}{*}{ Bulan } & \multirow{2}{*}{$\begin{array}{l}\text { Jumlah } \\
\text { Produksi } \\
\text { (unit) }\end{array}$} & \multirow{2}{*}{$\begin{array}{c}\text { Sampel } \\
\text { (unit) }\end{array}$} & \multicolumn{3}{|c|}{ Jenis Kecacatan (unit) } & \multirow{2}{*}{$\begin{array}{c}\text { Jumlah } \\
\text { Cacat } \\
\text { (unit) }\end{array}$} \\
\hline & & & & $\begin{array}{l}\text { Panel } \\
\text { Back } \\
\text { Penyok } \\
\text { (unit) }\end{array}$ & $\begin{array}{c}\text { Urethan } \\
\text { e Foam } \\
\text { Bocor } \\
\text { (unit) }\end{array}$ & $\begin{array}{l}\text { Panel } \\
\text { Back } \\
\text { Keluar } \\
\text { (unit) }\end{array}$ & \\
\hline 1 & 1 Agustus 2018 & 968 & 50 & 2 & 34 & 2 & 38 \\
\hline 2 & 2 Agustus 2018 & 1.165 & 50 & 5 & 12 & 3 & 20 \\
\hline 3 & 3 Agustus 2018 & 1.213 & 50 & 3 & 17 & 5 & 25 \\
\hline 4 & 6 Agustus 2018 & 1.086 & 50 & 7 & 11 & 9 & 27 \\
\hline 5 & 7 Agustus 2018 & 1.304 & 50 & 5 & 20 & 7 & 32 \\
\hline 6 & 8 Agustus 2018 & 1.453 & 50 & 12 & 19 & 4 & 35 \\
\hline 7 & 9 Agustus 2018 & 1.483 & 50 & 6 & 20 & 7 & 33 \\
\hline 8 & 10 Agustus 2018 & 1.213 & 50 & 2 & 22 & 1 & 25 \\
\hline 9 & 15 Agustus 2018 & 1.264 & 50 & 2 & 12 & 4 & 18 \\
\hline 10 & 16 Agustus 2018 & 1.359 & 50 & 1 & 29 & 6 & 36 \\
\hline \multirow[t]{3}{*}{11} & 18 Agustus 2018 & 1.286 & 50 & 4 & 27 & 7 & 38 \\
\hline & Total & 13.794 & 550 & 49 & 223 & 55 & 327 \\
\hline & \multicolumn{6}{|c|}{ Presentase } & $59.45 \%$ \\
\hline
\end{tabular}

c. Stratification

Dari data jenis dan jumlah cacat pada produk refrigerator maka dapat dilakukan pengklasifikasian data menjadi kelompok sejenis yang lebih kecil sehingga terlihat lebih jelas. Stratifikasi pada produk refrigerator ini didasarkan pada tiga jenis cacat yang disajikan pada Tabel 2.

Tabel 2 Stratification

\begin{tabular}{ccccc}
\hline \multicolumn{1}{c}{ Jenis Cacat } & $\begin{array}{c}\text { Jumlah } \\
\text { (unit) }\end{array}$ & $\begin{array}{c}\text { Jumlah } \\
\text { Komulatif (unit) }\end{array}$ & Presentase & $\begin{array}{c}\text { Presentase } \\
\text { Komulatif }\end{array}$ \\
\hline Urethane Foam Bocor & 223 & 223 & 68.2 & 68.2 \\
Panel Back Keluar & 55 & 278 & 16.8 & 85.0 \\
Panel Back Penyok & 49 & 327 & 15.0 & 100.0 \\
$\quad$ Total & 327 & & & \\
\hline
\end{tabular}

\section{d. Histogram}

Histogram berguna untuk memudahkan dalam melihat jenis produk cacat yang paling banyak terjadi sesuai dengan check sheet. Data produk cacat disajikan dalam bentuk grafik balok yang dibagi berdasarkan jenis produk cacat sehingga lebih jelas dalam membacanya. dibuat grafik batang (histogram) yang memperlihatkan komposisi jumlah produk cacat dari masing masing jenis produk cacat yang ditunjukan pada gambar 1 .

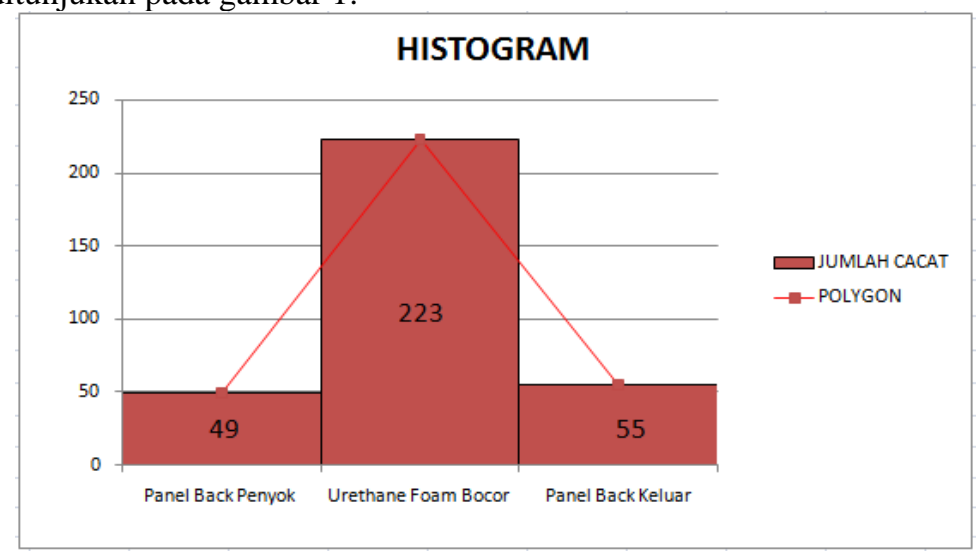

Gambar 1 Histogram 


\section{e. Diagram Pareto}

Setelah data produksi dan data kecacatan dari pengambilan sampel produk selama tanggal 1 Agustus - 18 Agustus 2018 terkumpul, maka langkah selanjutnya adalah membuat diagram pareto untuk memudahkkan dalam melihat mengecek presentase dari setiap jenis cacat yang terjadi.

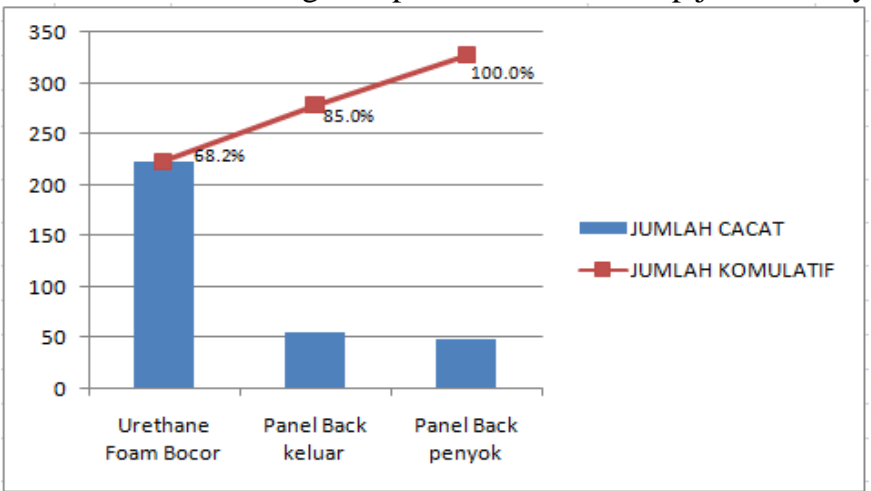

Gambar 2 Diagram Pareto

f. Peta Kendali

Berdasarkan data jumlah produk refrigerator, maka jumlah kerusakan setiap proses dapat diambil sampel pada tanggal 1 Agustus 2018 - 18 Agustus 2018. Dilanjutkan lagi dengan menganalisis data produk cacat untuk mengetahui sejauh mana kecacatan yang terjadi masih dalam batas kendali statistik melalui peta kendali. Peta kendali mempunyai manfaat untuk membantu pengendalian kualitas produk serta dapat memberikan informasi mengenai kapan dan dimana perusahaan harus melakukan perbaikan kualitas.

1. Peta kendali-p untuk jenis cacat Urethane Foam Bocor disajikan pada gambar 3.

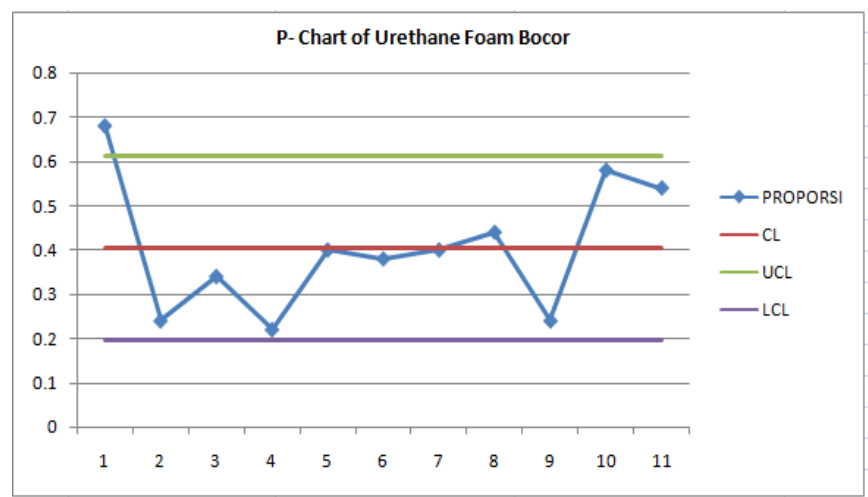

Gambar 3 Grafik Peta Kendali Cacat Urethane Foam Bocor

Berdasarkan grafik diatas dapat dilihat bahwa ada data yang melewati batas control UCL yaitu pada hari pertama sebesar 34 unit cacat maka data tersebut out of control, proporsi cacat urethane foam bocor tidak stabil disebabkan karena faktor bahan baku dan faktor pemasangan $P U$ Foam yang terburu-buru sehingga pemasangan tidak sesuai dan mengakibatkan urethane foam bocor pada pengisian cairan urethane di line urethane cabinet.

2. Perhitungan peta kendali-p untuk jenis cacat Panel Back Keluar disajikan pada gambar 4.

Berdasarkan grafik gambar 4. dapat dilihat bahwa tidak ada data yang melewati batas control UCL maka data tersebut tidak out of control. Namun proporsi cacat Panel Back Keluar tidak stabil disebabkan karena faktor pemasangan tape holding pada Cabinet shell yang kurang sehingga tipe tidak kuat menahan Panel Back dan mengakibatkan Panel Back keluar atau tidak rata dengan cabinet shell pada saat pengisian cairan urethane di line Urethane Cabinet.

3. Perhitungan peta kendali-p untuk jenis cacat Panel Back Penyok disajikan pada gambar 5.

Berdasarkan grafik gambar 5. dapat dilihat bahwa ada data yang melewati batas control UCL yaitu pada hari ke 6 UCL maka data tersebut out of control. proporsi cacat Panel Back Penyok tidak stabil disebabkan karena faktor operator kurang berhati-hati saat mensuplay cabinet shell ke line urethane dengan trolley cabinet dan penempatan Panel Back yang tidak sesuai sehingga Panel Back penyok. 


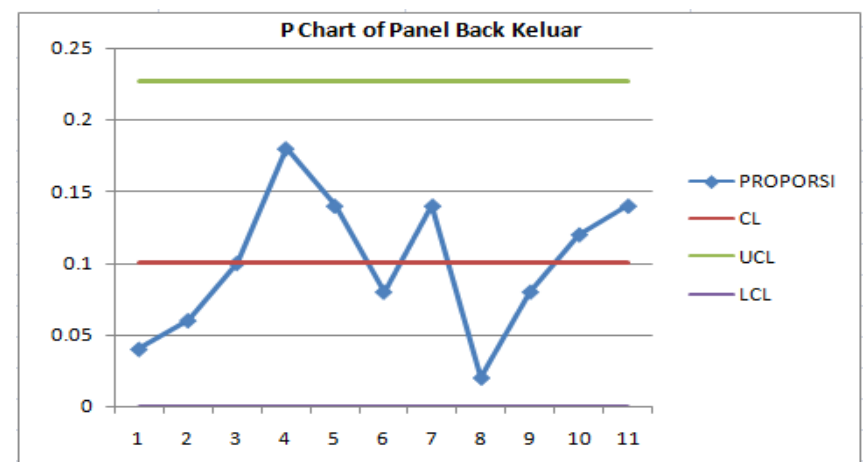

Gambar 4 Grafik Peta Kendali Cacat Panel Back Keluar

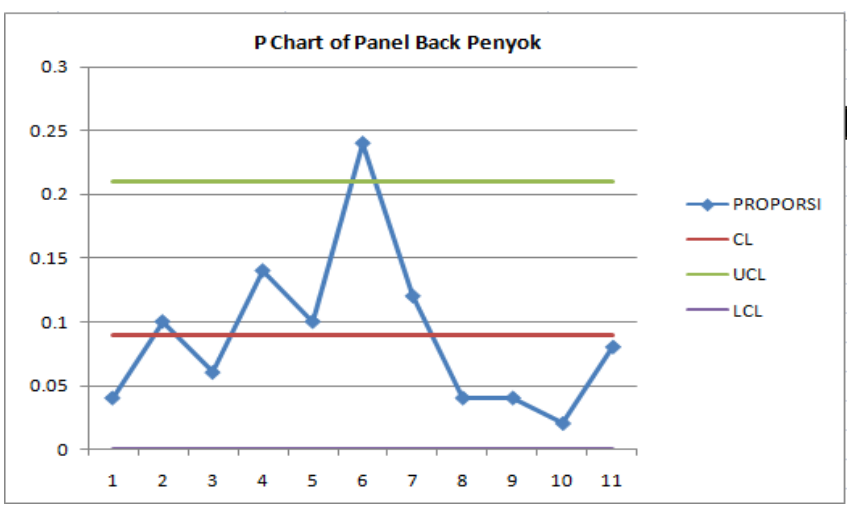

Gambar 5 Grafik Peta Kendali Cacat Panel Back Penyok

\section{g. Cause and Effect Diagram}

Setelah jenis-jenis produk cacat yang terjadi diketahui, selanjutnya perlu mengambil langkahlangkah perbaikan untuk mencegah maupun meminimalisir timbulnya produk cacat yang serupa. Sebelumnya dilakukan identifikasi dan pencarian penyebab timbulnya produk cacat pada produksi refrigerator. Sebagai alat bantu untuk mencari penyebab terjadinya produk cacat tersebut, digunakan diagram sebab akibat untuk menelusuri masing-masing produk cacat yang terjadi. Diagram sebab akibat cacat ditunjukan pada gambar 6.

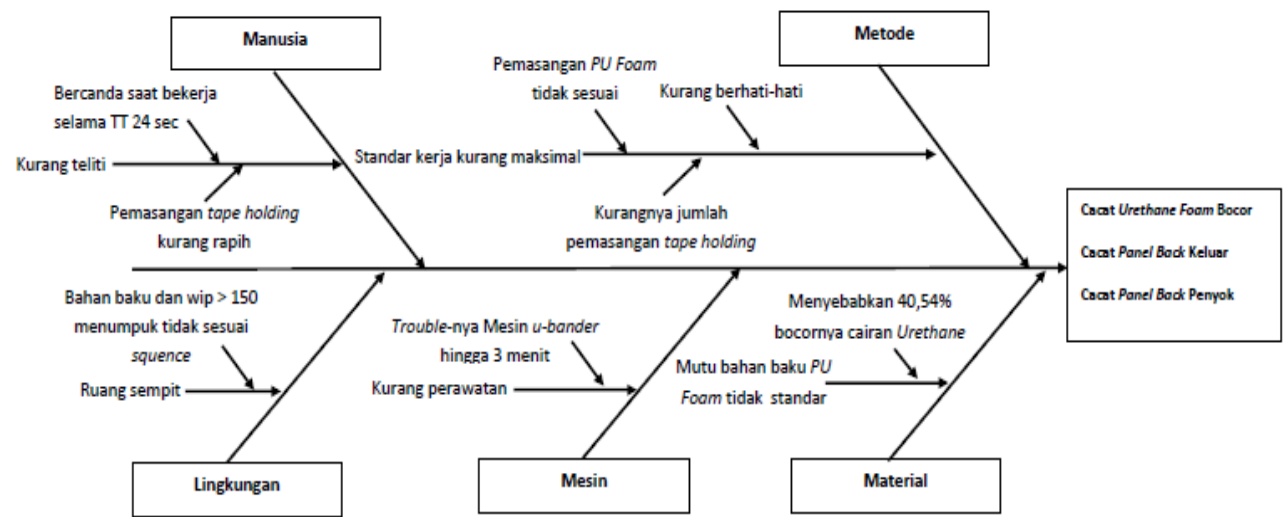

1. Faktor Manusia

Gambar 6 Diagram Fishbone Cacat Produk Refrigerator

Cacat Urethane Foam Bocor disebabkan karena operator sering bercanda dengan operator lain dari pengamatan waktu yang digunakan untuk mengobrol yaitu 15 seconds setiap waktu dari tack time 24 seconds berlangsung pada proses produksi, sehingga pengerjaan terburu-buru dan kurang teliti. Jenis cacat Panel Back Keluar disebabkan karena pemasangan tape holding kurang rapih pada panel back sehingga panel kurang kuat dan keluar saat pengisian urethane foam. Sedangkan pada jenis cacat Panel Back Penyok disebabkan karena operator kurang berhati-hati saat mensupply cabinet shell dengan trolley mengakibatkan panel back penyok terbentur dengan cabinet shell lain. 
2. Faktor Metode, standar kerja kurang maksimal yaitu:

a. Cacat Urethane Foam Bocor disebabkan karena kurang cepat dan rapih pada saat pemasangan $P U$ Foam sehingga pemasangan $P U$ Foam pada shell tidak sesuai, mengakibatkan cairan urethane bocor hingga 223 unit.

b. Cacat Panel Back keluar disebabkan karena kurangnya jumlah pemasangan tape holding pada panel back, mengakibatkan panel keluar.

c. Cacat Panel Back Penyok disebabkan operator kurang berhati-hati saat bekerja, sehingga panel back penyok.

3. Faktor Lingkungan, ruang pada operator sempit di perkirakan pada PCM line kurang dari 1 meter, terdapat bahan baku dan WIP $\geq 150$ yang tidak sesuai sequence sehingga operator kurang leluasa dalam berkerja.

4. Faktor Mesin, kurangnya perawatan pada mesin u-bander sehingga mengakibatkan mesin trouble saat beroprasi, mengakibatkan hilangnya 3 menit waktu proses pembutan cabinet shell, perawatan yang dilakukan perusuhaan hanya pada saat 2 minggu sekali, ataupun pada saat mesin trouble saja, seharusnya standar perawatan yaitu satu minggu sekali pada hari sabtu maupun minggu.

5. Faktor Material, bahan baku PU Foam yang digunakan kurang standar, bahan terlalu tipis tidak dapat menyerap cairan sehingga tidak mampu menahan cairan urethane, mengakibatkan $40,54 \%$ bocor.

\section{2 $\mathrm{DO}$}

Setelah membuat perencanaan perbaikan terhadap kecacatan produk yang terjadi pada proses produksi refrigerator di perusahaan PT. ' $\mathrm{X}$ ', maka langkah selanjutnya adalah melakukan dan melaksanakan usulan perbaikan pada proses produksi. Tindakan perbaikan dilakukan pada Business unit Refrigerator pada tanggal 19 Agustus - 31 Agustus 2018, tindakan yang dilakukan disajikan dengan menggunakan metode $5 \mathrm{~W}+1 \mathrm{H}$ pada tabel 3 .

Tabel 3 Perbaikan Menggunakan 5W $+1 \mathrm{H}$ pada Cacat Proses Produksi Refrigerator

\begin{tabular}{|c|c|c|c|c|c|}
\hline Faktor & Manusia & Material & Metode & Mesin & Lingkungan \\
\hline $\begin{array}{l}\text { What } \\
\text { (masalah } \\
\text { utama) }\end{array}$ & $\begin{array}{l}\text { Terjadinya cacat } \\
\text { Urethane Foam } \\
\text { Bocor, Panel Back } \\
\text { Keluar, Panel Back } \\
\text { Penyok }\end{array}$ & $\begin{array}{l}\text { Bahan Baku } P U \\
\text { Foam tidak } \\
\text { mampu menahan } \\
\text { cairan Urethane } \\
\text { Foam }\end{array}$ & $\begin{array}{l}\text { Operator kurang } \\
\text { cepat dan rapih. }\end{array}$ & $\begin{array}{l}\text { Mesin } u \text {-bander } \\
\text { seringkali trouble }\end{array}$ & $\begin{array}{l}\text { Lingkungan } \\
\text { operator sempit }\end{array}$ \\
\hline $\begin{array}{l}\text { Why (alas } \\
\text { an) }\end{array}$ & $\begin{array}{l}\text { a. Cacat Urethane } \\
\text { Foam Bocor, } \\
\text { Operator kurang } \\
\text { teliti dan sering } \\
\text { bercanda pada } \\
\text { setiap waktu } \\
\text { tack time } 24 \\
\text { seconds } \\
\text { berlangsung } \\
\text { selama proses } \\
\text { produksi } \\
\text { sehingga } \\
\text { pengerjaan } \\
\text { terburu-buru } \\
\text { dan kurang } \\
\text { teliti. } \\
\text { Cacat Panel } \\
\text { Back Keluar, } \\
\text { disebabkan } \\
\text { karena Kurang } \\
\text { kuatnya } \\
\text { pemasangan } \\
\text { tape holding } \\
\text { pada panel } \\
\text { back sehingga } \\
\text { mengakibatkan } \\
\text { panel back }\end{array}$ & $\begin{array}{l}\text { Mutu bahan } \\
\text { bahan } P U \text { Foam } \\
\text { yang digunakan } \\
\text { kurang standar, } \\
\text { bahan terlalu tipis } \\
\text { tidak dapat } \\
\text { menyerap cairan } \\
\text { sehingga tidak } \\
\text { mampu menahan } \\
\text { cairan urethane, } \\
\text { mengakibatkan } \\
\text { 40,54\% bocor. }\end{array}$ & $\begin{array}{l}\text { Urethane } \\
\text { foam bocor } \\
\text { disebabkan } \\
\text { standar kerja } \\
\text { kurang } \\
\text { maksimal } \\
\text { yaitu } \\
\text { rapihnya saat } \\
\text { pemasangan } \\
\text { PU Foam } \\
\text { sehingga } \\
\text { pemasangan } \\
\text { PU Foam } \\
\text { pada shell } \\
\text { tidak sesuai, } \\
\text { mengakibatk } \\
\text { an cairan } \\
\text { urethane } \\
\text { bocor hingga } \\
\text { 384 unit. } \\
\text { Panel back } \\
\text { keluar } \\
\text { disebabkan } \\
\text { karena } \\
\text { kurangnya } \\
\text { pemasangan } \\
\text { tape pada }\end{array}$ & $\begin{array}{l}\text { Kurangnya } \\
\text { perawatan pada } \\
\text { mesin } u \text {-bander } \\
\text { sehingga } \\
\text { mengakibatkan } \\
\text { mesin trouble saat } \\
\text { beroprasi, } \\
\text { mengakibatkan } \\
\text { hilangnya } 3 \text { menit } \\
\text { waktu proses } \\
\text { pembutan cabinet } \\
\text { shell, perawatan } \\
\text { yang dilakukan } \\
\text { perusuhaan hanya } \\
\text { pada saat } 2 \text { minggu } \\
\text { sekali, ataupun pada } \\
\text { saat mesin trouble } \\
\text { saja, seharusnya } \\
\text { standar perawatan } \\
\text { yaitu satu minggu } \\
\text { sekali pada hari sabtu } \\
\text { maupun hari minggu. }\end{array}$ & $\begin{array}{l}\text { Lingkungan } \\
\text { pada operator } \\
\text { sempit, di } \\
\text { perkirakan pada } \\
\text { PCM line kurang } \\
\text { dari } 1 \text { meter, } \\
\text { terdapat bahan } \\
\text { baku yang } \\
\text { menumpuk dan } \\
\text { WIP } \geq 150 \text { yang } \\
\text { tidak sesuai } \\
\text { sequence } \\
\text { sehingga } \\
\text { operator kurang } \\
\text { leluasa dalam } \\
\text { berkerja. }\end{array}$ \\
\hline
\end{tabular}




\begin{tabular}{|c|c|c|c|c|c|}
\hline Faktor & Manusia & Material & Metode & Mesin & Lingkungan \\
\hline & $\begin{array}{l}\text { keluar. } \\
\text { c. Cacat Panel } \\
\text { Back penyok } \\
\text { disebabkan } \\
\text { karena saat } \\
\text { mensuplay } \\
\text { cabinet shell ke } \\
\text { line URC } \\
\text { kurang berhati- } \\
\text { hati sehingga } \\
\text { mengakibatkan } \\
\text { panel back } \\
\text { terbentur } \\
\text { dengan cabinet } \\
\text { shell lain. }\end{array}$ & & $\begin{array}{l}\text { panel back. } \\
\text { c. } \\
\text { Panel back } \\
\text { penyok } \\
\text { dikarenakan } \\
\text { operator } \\
\text { bagian supply } \\
\text { cabinet shell } \\
\text { kurang } \\
\text { berhati-hati. }\end{array}$ & & \\
\hline $\begin{array}{l}\text { When } \\
\text { (kapan) }\end{array}$ & $\begin{array}{l}\text { Saat proses produksi } \\
\text { refrigerator }\end{array}$ & $\begin{array}{l}\text { Ketika sudut shell } \\
\text { dipasang bahan } \\
\text { baku PU Foam }\end{array}$ & $\begin{array}{l}\text { Pada proses } \\
\text { pemasangan } \\
\text { bahan baku } P U \\
\text { Foam, } \\
\text { Pemasanggan } \\
\text { tape, dan pada } \\
\text { saat proses } \\
\text { supplay cabinet } \\
\text { shell }\end{array}$ & $\begin{array}{l}\text { Pada proses } \\
\text { pembentukan cabinet } \\
\text { shell }\end{array}$ & $\begin{array}{l}\text { Saat proses } \\
\text { produksi } \\
\text { berlangsung }\end{array}$ \\
\hline $\begin{array}{l}\text { Who } \\
\text { (siapa) }\end{array}$ & $\begin{array}{l}\text { Operator pada line } \\
\text { PCM }\end{array}$ & $\begin{array}{l}\text { Bahan baku } P U \\
\text { foam }\end{array}$ & $\begin{array}{l}\text { Operator pada } \\
\text { line PCM }\end{array}$ & Bagian Maintenance & $\begin{array}{l}\text { Pengatur } \\
\text { lingkungan } \\
\text { produksi }\end{array}$ \\
\hline $\begin{array}{l}\text { How } \\
\text { (tindakan) }\end{array}$ & $\begin{array}{l}\text { a. } \\
\text { sosiakukan } \\
\text { peningkatan } \\
\text { kesadaran } \\
\text { terhadap } \\
\text { operator. } \\
\text { b. Melakukan } \\
\text { pengawasan } \\
\text { langsung pada } \\
\text { saat proses } \\
\text { produksi } \\
\text { berlangsung, } \\
\text { dapat berupa } \\
\text { pengawasan } \\
\text { langsung } \\
\text { ditempat } \\
\text { produksi } \\
\text { maupun } \\
\text { menambahkan } \\
\text { CCTV pada } \\
\text { area produksi. } \\
\text { Memberikan } \\
\text { peringatan jika } \\
\text { ada operator } \\
\text { yang melakukan } \\
\text { kesalahan. }\end{array}$ & $\begin{array}{l}\text { Menyeleksi dan } \\
\text { mengganti bahan } \\
\text { baku } P U \text { Foam } \\
\text { dengan A20 } \\
\text { karena jenis } \\
\text { bahan baku ini } \\
\text { mampu menyerap } \\
\text { cairan dan } \\
\text { memiliki } \\
\text { ketebalan } 1,5 \mathrm{~cm} .\end{array}$ & $\begin{array}{l}\text { Memberikan } \\
\text { arahan dan } \\
\text { bimbingan } \\
\text { terhadap operator } \\
\text { lebih sering } \\
\text { berupa cara } \\
\text { proses produksi } \\
\text { yang sesuai } \\
\text { secara langsung } \\
\text { maupun saat } \\
\text { brefing sebelum } \\
\text { proses produksi } \\
\text { berlangsung. }\end{array}$ & $\begin{array}{l}\text { Melakukan } \\
\text { pengecekan kesiapan } \\
\text { mesin sebelum dan } \\
\text { sesuadah melakukan } \\
\text { proses produksi, } \\
\text { serta melakukan } \\
\text { perawatan mesin } \\
\text { setiap satu minggu } \\
\text { sekali pada hari sabtu } \\
\text { maupun hari minggu } \\
\text { tidak hanya ketika } \\
\text { mesin rusak. }\end{array}$ & $\begin{array}{l}\text { Menambah } \\
\text { fasilitas } \\
\text { penempatan } \\
\text { bahan baku agar } \\
\text { memberikan luas } \\
\text { lingkungan } \\
\text { sekitar } 1 \text { meter } \\
\text { yang berguna } \\
\text { untuk } \\
\text { merapihkan } \\
\text { bahan baku yang } \\
\text { menumpuk di } \\
\text { tempat produksi, } \\
\text { dan melakukan } \\
\text { perbaikan pada } \\
\text { penjadwalan } \\
\text { pada stasiun } \\
\text { Inner Assy. }\end{array}$ \\
\hline
\end{tabular}

\section{3. $\mathrm{CHECK}$}

Setelah melakukan tindakan dari tahap $D O$, langkah selanjutnya yaitu memeriksa kembali apakah tindakan perbaikan dengan sosialisasi terhadap karyawan, perbaikan mesin, dan penggantian bahan baku A20 dapat mengurangi jumlah kecacatan produk pada produksi refrigerator di PT. 'X' .

\section{Check Sheet}

Pengumpulan data sampel berupa jumlah produksi, jumlah cacat, dan jenis jumlah cacat dari pencatatan check sheet yang dilakukan oleh PT. 'X', data sampel yang digunakan adalah pengambilan dari data sampel dalam produksi dari data kecacatan produk refrigerator pada tanggal 
19 Agustus 2018 - 31 Agustus 2018, bertujuan untuk memeriksa kembali apakah tindakan perbaikan yang dilakukan dapat mengurangi jumlah kecacatan produk refrigerator.

\begin{tabular}{|c|c|c|c|c|c|c|c|}
\hline \multirow[t]{2}{*}{ No } & \multirow{2}{*}{ Bulan } & \multirow{2}{*}{$\begin{array}{l}\text { Jumlah } \\
\text { Produksi } \\
\text { (unit) }\end{array}$} & \multirow{2}{*}{$\begin{array}{c}\text { Sampel } \\
\text { (unit) }\end{array}$} & \multicolumn{3}{|c|}{ Jenis Kecacatan (unit) } & \multirow{2}{*}{$\begin{array}{c}\text { Jumlah Cacat } \\
\text { (unit) }\end{array}$} \\
\hline & & & & $\begin{array}{l}\text { Panel Back } \\
\text { Penyok } \\
\text { (unit) }\end{array}$ & $\begin{array}{l}\text { Urethane } \\
\text { Foam Bocor } \\
\text { (unit) }\end{array}$ & $\begin{array}{l}\text { Panel Back } \\
\text { Keluar } \\
\text { (unit) }\end{array}$ & \\
\hline 1 & 19 Agustus 2018 & 698 & 50 & 5 & 18 & 5 & 28 \\
\hline 2 & 20 Agustus 2018 & 1.714 & 50 & 3 & 17 & 3 & 23 \\
\hline 3 & 21 Agustus 2018 & 1.428 & 50 & 2 & 15 & 2 & 19 \\
\hline 4 & 23 Agustus 2018 & 1.823 & 50 & 4 & 12 & 3 & 19 \\
\hline 5 & 24 Agustus 2018 & 1.965 & 50 & 2 & 14 & 2 & 18 \\
\hline 6 & 25 Agustus 2018 & 2.059 & 50 & 3 & 16 & 3 & 22 \\
\hline 7 & 26 Agustus 2018 & 541 & 50 & 2 & 14 & 2 & 18 \\
\hline 8 & 27 Agustus 2018 & 2.189 & 50 & 1 & 12 & 2 & 15 \\
\hline 9 & 28 Agustus 2018 & 770 & 50 & 2 & 13 & 3 & 18 \\
\hline 10 & 29 Agustus 2018 & 714 & 50 & 1 & 11 & 2 & 14 \\
\hline 11 & 30 Agustus 2018 & 1359 & 50 & 2 & 10 & 1 & 13 \\
\hline \multirow[t]{3}{*}{12} & 31 Agustus 2018 & 1.453 & 50 & 1 & 9 & 2 & 12 \\
\hline & Total & 16.713 & 600 & 28 & 161 & 30 & 219 \\
\hline & Persentase & $36,50 \%$ & & & & & \\
\hline
\end{tabular}

Tabel 4 menyajikan jumlah total produk cacat setelah perbaikan berjumlah 219 unit. Sedangkan pada tabel 1 menyajikan jumlah total produk cacat sebelum perbaikan berjumlah 327 unit. Maka telah terjadi penurunan jumlah produk cacat setelah dilakukan perbaikan.

2. Peta Kendali

Evaluasi juga dilakukan dengan peta kendali $\mathrm{p}$ untuk mengetahui apakah proses produksi refrigerator setelah adanya usulan perbaikan stabil atau tidak.

a. $\quad$ Peta kendali untuk jenis cacat Urethane Foam Bocor disajikan pada gambar 8 .

Berdasarkan grafik gambar 8. dapat dilihat bahwa tidak ada data yang melewati batas control UCL maka data tersebut tidak out of control. Proporsi cacat sudah stabil, hal tersebut dikarenakan sudah melakukan perbaikan dan trial penggantian bahan baku dan menjalankan standar kerja operator, sehingga pada tanggal 19 Agustus - 31 Agustus cacat lebih rendah dibandingkan dengan data sebelum trial atau sebelum melakukan tindakan perbaikan.

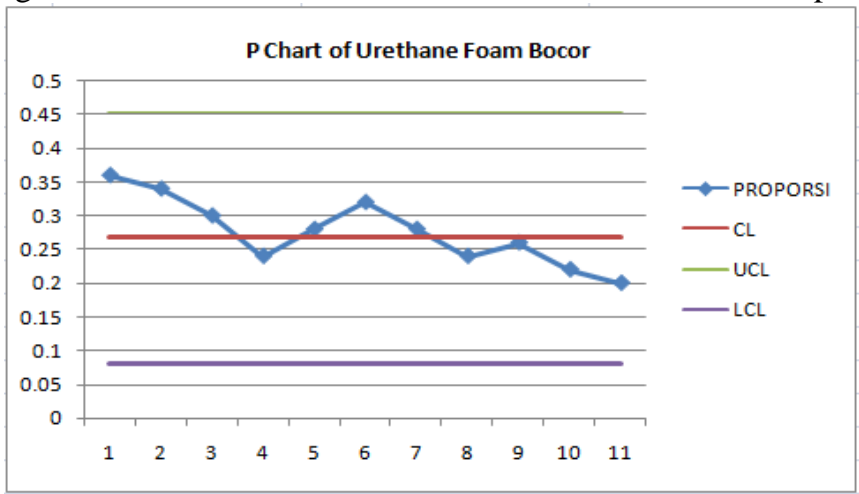

Gambar 8 Peta Kendali Cacat Urethane Foam Bocor

b. Peta kendali untuk jenis cacat Panel Back Keluar disajikan pada gambar 9.

Berdasarkan grafik gambar 9. dapat dilihat bahwa tidak ada data yang melewati batas control UCL maka data tersebut tidak out of control. Proporsi cacat sudah stabil, hal tersebut dikarenakan sudah melakukan perbaikan dan trial penambahan pemasangan tape holding pada cabinet shell sehingga jumlah cacat pada tanggal 19 Agustus - 31 Agustus lebih rendah dibandingkan dengan data sebelum melakukan tindakan perbaikan.

c. Peta kendali untuk jenis cacat Panel Back Penyok disajikan pada gambar 10.

Berdasarkan grafik gambar 10. dapat dilihat bahwa tidak ada data yang melewati batas control UCL maka data tersebut tidak out of control. Proporsi cacat sudah stabil, hal tersebut dikarenakan sudah melakukan perbaikan dan trial penempatan penyususnan panel back yang sesuai dan operator bekerja lebih berhati-hati sehingga jumlah cacat pada tanggal 19 Agustus - 
31 Agustus lebih rendah dibandingkan dengan data sebelum trial atau sebelum melakukan tindakan perbaikan.

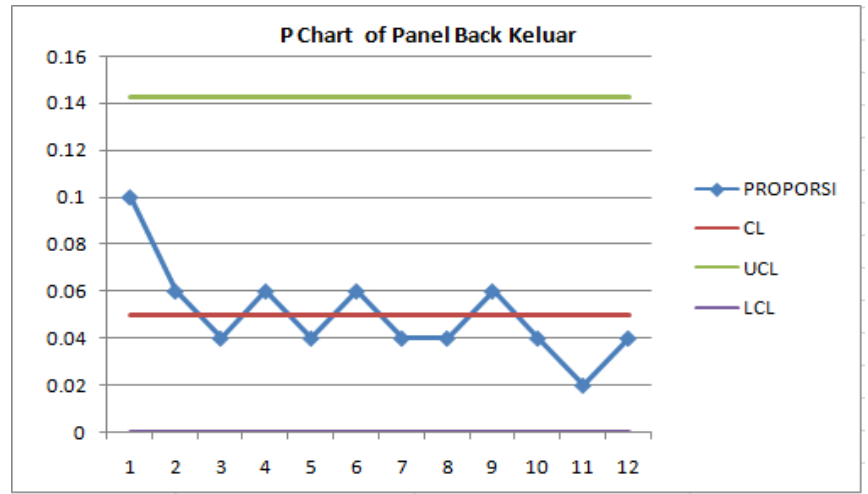

Gambar 9 Peta Kendali Cacat Panel Back Keluar

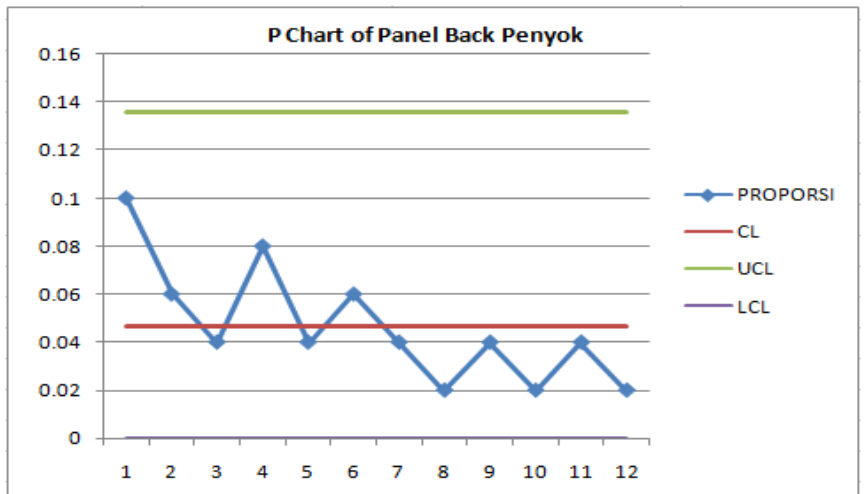

Gambar 10 Peta Kendali Cacat Panel Back Penyok

\subsection{ACTION}

Setelah dilakukan beberapa tindakan perbaikan pada kegiatan produksi pada tanggal 19 Agustus - 31 Agustus dan pengecekan kembali terhadap hasil perbaikan, dapat diketahui bahwa permasalahan kualitas yang terjadi di PT. ' $\mathrm{X}$ ' telah dapat diminimalisir. Langkah selanjutnya yang harus dilakukan adalah mempertahankan hasil pengendalian kualitas yang telah tercapai untuk mencegah terulangnya masalah yang sama dan lebih meminimalkan tingkat kecacatan produk pada kegiatan produksi selanjutnya dengan menetapkan standar bagi perusahaan setelah melakukan perbaikan. Tabel 5 menyajikan standarisasi kegiatan proses produksi refrigerator.

Tabel 5 Standarisasi Proses Produksi Refrigerator PT. ' $\mathrm{X}$ '

\begin{tabular}{|c|c|c|c|}
\hline No & Faktor & Standar Normal & Standar Perusahaan Setelah Perbaikan \\
\hline 1 & Manusia & $\begin{array}{l}\text { Operator harus disiplin } \\
\text { dan tidak bercanda saat } \\
\text { proses produksi } \\
\text { berlangsung }\end{array}$ & $\begin{array}{l}\text { Kepala produksi harus lebih sering melakukan } \\
\text { pengawasan secara langsung maupun } \\
\text { menambahkan CCTV pada area produksi. }\end{array}$ \\
\hline 2 & Metode & $\begin{array}{l}\text { Menetapkan Standar } \\
\text { kerja perusahaan agar } \\
\text { presentase kecacatan } \\
\text { tidak melebihi } 36,50 \%\end{array}$ & $\begin{array}{l}\text { Melakukan bimbingan dan arahan pengendalian } \\
\text { kualitas pada saat brefing sebelum proses } \\
\text { produksi bertujuan untuk menerapkan standar } \\
\text { kerja. }\end{array}$ \\
\hline 3 & Lingkungan & $\begin{array}{l}\text { Sesuai dengan perturan } \\
\text { pada } 5 \text { komitmen } \\
\text { perusahaan yang } \\
\text { menetapkan area kerja } \\
\text { aman, dan standar WIP } \\
\text { tidak melebihi } 150\end{array}$ & $\begin{array}{l}\text { Melakukan perencanaan supply bahan baku } \\
\text { sesuai sequence produksi }\end{array}$ \\
\hline 4 & Mesin & $\begin{array}{l}\text { Mesin produksi dapat } \\
\text { berfungsi dengan baik } \\
\text { selama } 8 \text { jam waktu } \\
\text { kerja pada hari senin - } \\
\text { jumat }\end{array}$ & $\begin{array}{l}\text { Maintenance mesin harus selalu melakukan } \\
\text { pengecekan mesin sebelum dan sesudah proses } \\
\text { produksi, serta melakukan perawatan mesin } \\
\text { setiap satu minggu sekali pada hari sabtu } \\
\text { maupun hari minggu tidak hanya ketika mesin }\end{array}$ \\
\hline
\end{tabular}




\begin{tabular}{|c|c|c|c|}
\hline No & Faktor & Standar Normal & Standar Perusahaan Setelah Perbaikan \\
\hline & & & rusak. \\
\hline 5 & Material & $\begin{array}{l}\text { Bahan baku pada sisi } \\
\text { shell harus dapat } \\
\text { menahan cairan } \\
\text { urethane agar tidak } \\
\text { terjadi kebocoran }\end{array}$ & $\begin{array}{l}\text { Mengganti bahan baku jenis } P U \text { Foam dengan } \\
\text { bahan baku jenis A20 karena jenis bahan baku } \\
\text { ini mampu menyerap cairan dan jenis A20 } \\
\text { memiliki ketebalan } 1,5 \mathrm{~cm} \text {. }\end{array}$ \\
\hline
\end{tabular}

\section{SIMPULAN}

Berdasarkan pengendalian kualitas dengan metode PDCA dengan alat bantu seven tools pada produksi refrigerator di PT. ' $\mathrm{X}$ ' yang dilakukan pada tanggal 19 Agustus 2018 - 31 Agustus 2018, melakukan tindakan perbaikan pengendalian kualitas dengan meningkatkan kesadaran operator, meningkatkan standar kerja, mengatur lingkungan produksi, perawatan perbaikan mesin $u$-bander, dan penggantian bahan baku $P U$ foam dengan A20, didapat hasil pengendalian menunjukan presentase sebesar 36,50\%, Maka tindakan perbaikan mampu meminimalisir kecacatan sebesar 22,95\%. Pengendalian kualitas perlu dilakukan terus menerus agar lebih menekankan presentase produk cacat menjadi lebih kecil.

\section{DAFTAR PUSTAKA}

Atmaja L.T, Supriadi E, dan Utaminingsih S., (2018). Analisis Efektivitas Mesin Pressing Ph-1400 Dengan Metode Overall Equipment Effectiveness (OEE) Di PT. Surya Siam Keramik. Jurnal Teknologi Universitas Pamulang. Vol.1(1), Hlm. 9.

Fauza, Q., Kautsar, AP., (2018). Review Artikel Plan Do Check Action (PDCA) dalam meningkatan kualitas pelayanan kesehatan di rumah sakit. Jurnal Farmaka, Vol. 16(3), 234 - 243.

Gasperz, Vincent. (2005). Total Quality Management. Jakarta: PT. Gramedia Pustaka Utama.

Heizer, Jay and Render, B., (2006). Operations Management (Manajemen Operasi), Jakarta: Salemba Empat. Isniah, S., Purba, HH., Debora, F., (2020). Plan Do Check Action (PDCA) Method : Literature Review and Research Issue. Jurnal Sistem dan Manajemen Industri. Vol. 4(1), 72 -81

Mitra, Amitava. (2008). Fundamental of Quality Control and Improvement. John Wiley \& Sons. Inc., New Jersey.

Montgomery, Douglas C., (2016). Introduction to Statistical Quality Control. John Wiley \& Sons. Inc. USA.

Silva, Adriana S., Carla F. Medeiros, Raimundo Kennedy Vieira. (2017). Cleaner Production and PDCA Cycle : Practical Application For Reducing The Cans Loss Index in a Beverage Company. Journal of Cleaner Production, Vol. 150, 324 - 338.

Setyawan A., Subali, (2016). The Implementation of Seven Quality Management Tools. Jurnal Ilmiah Mahasiswa Universitas Surabaya Vol.6(2).

Sokovic, M., D. Pavletic, K. Kern Pipan. (2010). Quality Improvement Methodologies PDCA Cycles, RADAR Matrix, DMAIC and DFSS. Journal Of Achievements in Material and Manufacturing Engineering. Valume 43 Issue 1.

Utami, S., Djamal, AH. (2018). Implementasi Pengendalian Kualitas Produk XX Kaplet pada proses pengemasan primer dengan penerapan konsep PCDA. Jurnal Integrasi Sistem Industri. Vol. 5(2).

Yulianto \& Al-faritsy. (2016). Perbaikan Kualitas Produk Wajan Dengan Menggunakan Metode Six Sigma Dan Kano. Jurnal Ilmiah Teknik Industri, Vol. 14(2). 